\title{
Dry powder inhalers: a concise summary of the electronic monitoring devices
}

\author{
Piyush Pradeep Mehta*,1 \\ ${ }^{1}$ Department of Quality Assurance Techniques, Poona College of Pharmacy, Bharati Vidyapeeth University, Pune, Maharashtra 411 \\ 038, India \\ *Author for correspondence: Tel.: +91202543 7237; Fax: +91 202543 9383; piyu053@gmail.com
}

"Monitoring devices not only permit primary therapy adherence monitoring but can also offer in-depth data regarding the inhaler handling technique and pulmonary fitness such as inhaler resistance, inhalation volume and peak inspiratory flow more precisely."

First draft submitted: 30 July 2020; Accepted for publication: 19 August 2020; Published online: 2 September 2020

Keywords: digital inhalers • diskus adherence logger • dry powder inhalers • electronic monitoring devices - Enerzair ${ }^{\circledR}$ Breezhaler ${ }^{\circledR} \bullet$ patient information leaflet $\bullet$ ProAir ${ }^{\circledR}$ Digihaler ${ }^{T M} \bullet$ Respiro ${ }^{\circledR}$ device $\bullet$ SmartTurbo $\bullet$ therapy adherence

\section{Pulmonary drug delivery}

Pulmonary diseases affect more than 500 million people globally and are the leading causes of death and disability worldwide [1]. A variety of therapeutic options, such as dry powder inhalers (DPIs), pressurized metered-dose inhalers, soft mist inhalers and nebulizers have been methodically probed for the management of respiratory diseases [1-3]. Among them, DPIs are the most commonly prescribed dosage forms due to their aptness for delivering a variety of molecules, better physicochemical stability and satisfactory patient compliance [3-5]. Furthermore, to maximize the clinical outcome of DPI therapy, several formulation technologies (e.g., dry powder coating, PulmoSphere ${ }^{T M}$ and/or Technosphere ${ }^{\circledR}$ ), inhaler devices (Adasuve ${ }^{\circledR}$, Inbrija ${ }^{\circledR}$, Twincer ${ }^{\circledR}$ and DirectHaler ${ }^{T M}$ ) and excipients (e.g., lactose crystals, mannitol and magnesium stearate) have been thoroughly investigated [3,4]. Despite great efforts on DPIs for pulmonary disease, adherence to pulmonary therapy is frequently suboptimal [6].

The patient adherence and compliance to inhalation therapy are the major challenges faced by clinicians during routine clinical practices [7]. The successful inhalation therapy is $10 \%$ medication and $90 \%$ education [8]. The patient adherence to long-term therapy in respiratory diseases averages $50 \%$ in developed nations [7]. This setback is because of the failure of helpful dialogue between clinicians and patients during the therapy [9]. The available 'apt' means for patient education and training is the package insert, a printed instruction for use or a patient information leaflet [9]. But, these mean that they are unable to answer the problems regarding patient education and compliance with the therapy. Therefore, dynamic scientists and clinicians are working on the various electronic monitoring devices to provide a more informed dialogue between the clinicians and patients during long-term pulmonary therapy.

\section{Electronic monitoring devices}

Electronic monitoring devices such as aerosol actuation counter and nebulizer chronolog (Forefront Engineering Corporation, USA) were designed at the beginning of the 1990s and have been developing, primarily for the evaluation of medication adherence [10]. However, with the beginning of the 20th century, a variety of sensing technologies, in other words, Bluetooth Low Energy module and system on chip and mechanical switches have been tried and tested for the development of absolute digital inhaler devices [11]. Additionally, micro or nano electro-mechanical pressure sensor systems are also specially designed for better inhaler devices for handling and adherence data monitoring [11]. For instance, ProAir ${ }^{\circledR}$ Digihaler $^{T M}$ (Teva Pharmaceutical Industries Ltd, Israel) or Enerzair ${ }^{\circledR}$ Breezhaler ${ }^{\circledR}$ (Novartis, Switzerland), digital devices have made a noteworthy impact on the medication 
adherence and inhaler device handling, which greatly helps healthcare professionals and patients. The electronic monitoring devices and digital inhalers that are investigated and analyzed for DPIs are reviewed below.

\section{Amiko technology}

The Amiko (London, UK) is a global corporation focused on the design and development of digital medicines to tackle the medical needs of clinicians and patients [12]. Respiro ${ }^{\circledR}$ is Amiko's primary digital platform that improves pulmonary care through the unique sensing technology, artificial intelligence and digital expertise. It is an electronic monitoring device to support clinicians and patients in monitoring and recording inhaler device handling [12,13]. It has been designed and developed for available inhaler devices without any need for modification on the inhaler device itself. It did not hinder the airflow pathway, dose-

delivery efficacy and typical patient handling of the inhaler device. It integrates machine learning algorithms with sensor technology to register various events, for example the inhaler orientation during the inhalation, the patient's inspiratory effort, the inhalation maneuver and the inhaler device dose loading method. Particularly, it contains the micro-electro-mechanical system (MEMS) sensors that allow steady digital feedback for each critical movement during the actuation of the inhaler device [12,13]. The Respiro device is attuned with the 'Respiro Mobile' software application, which presents data on adherence patterns and inhaler performance. Moreover, the Respiro device collects the data and wirelessly exchanges it with a paired Smartphone or a computer [12,13].

Recently, Braido et al. evaluated the functioning of the Amiko ${ }^{\circledR}$ device as an electronic monitoring device for the understanding of inhaler operation, on a variety of marketed multi-dose DPIs, in other words, Spiromax ${ }^{\circledR}$ (Teva Pharmaceutical Industries Ltd, Israel), Ellipta ${ }^{\circledR}$ (GlaxoSmithKline, UK) and NEXThaler ${ }^{\circledR}$ (Chiesi Farmaceutici S.p.A., Italy). Particularly, Braido et al. studied the resistance of each inhaler device with and without the Amiko device, inhalation maneuver, patient's inspiratory effort, inhaler device dose loading method and inhaler device orientation during inhalation. The inhaler device resistances with the Amiko device were the lessor of four orders of degree, compared with the intrinsic resistance of the inhalers. Therefore, differences in inhaler device resistances with the Amiko device were clinically negligible. The Amiko device was found to be over 99\% precise in sensing the performed inhalation maneuver. Moreover, the Amiko device monitors the patient's inspiratory effort, in other words, the duration of the inhalation and the peak inspiratory flow with a mean absolute error smaller than $180 \mathrm{~ms}$ and $8.16 \mathrm{l} / \mathrm{min}$, respectively. Furthermore, all the drug loading movements were registered precisely for each inhaler device and monitor device orientation during inhalation with a mean absolute error lesser than $3.53^{\circ}$ for the three inhaler devices [12]. Similar results were also reported by Rogueda et al. for the capsule and blister based Merxin DPIs, MRX003 and MRX001. Merxin DPIs showed accuracy values around 90\% and above for all key respiratory parameters, showing that the combination of the Amiko technology with Merxin DPIs can be utilized to precisely estimate key measures of inhaler handling and pulmonary health [13]. Concisely, the unique features of the Amiko technology represented a significant platform to recognize, store and share key data for adherence improvement and device misuse correction.

\section{Inhaler Compliance Assessment Device}

The Inhaler Compliance Assessment Device (INCA) is designed and developed by a multidisciplinary group of clinicians, pharmacists, engineers and psychologists working on various key aspects of the inhaler technique and adherence to gain an absolute understanding of inhaler device functioning [14]. The INCA is an acoustic sensing device (photonic sensing technology), containing a small battery-operated microphone, a microprocessor and solidstate memory storage. The actuation of the inhaler starts an audio record that cautiously reports the audio-related with the inhalation maneuver and this audio record ends once the inhaler device is closed [14]. All audio dossiers are time-stamped and saved on solid-state memory storage until the INCA information is transferred to the correct workstation. An automated algorithm wave processing and time-series assessment offers quantitative data on time, inhaler handling and the interval of inhaler usage. The acoustic sensing permit recognizes every step of inhaler use and can as a result notice system errors, such as failure to prime the inhaler, low inhalation flow, dispersion of the powder by exhaling into the mouthpiece, dose dumping, etc [14]. Several investigations have confirmed INCA as a technique for the assessment of inhaler devices and for revealing errors, for example, the exhalation into the DPI, dose-timing errors and account for missed doses [15]. INCA allows a more clinically precise assessment of patient inhaler practice as compared with standard checklist methods [16]. Moreover, personalized adherence studies using INCA showed clinical and economic advantages for asthmatic and chronic obstructive pulmonary disease patients $[17,18]$. Besides, INCA also helps to evaluate peak inspiratory flow rate and reveals whether a 
patient produced enough peak inspiratory flow rate to efficiently de-agglomerate particles from the DPI [19]. Briefly, effective inhaler handling and monitoring can be easily performed by the INCA device.

\section{Diskus Adherence Logger}

Advair Diskus ${ }^{\mathrm{TM}}$ is a next-generation, multi-dose inhaler design and is developed by GlaxoSmithKline, UK. Advair Diskus is used as a combination product containing a corticosteroid (fluticasone propionate) and a long-acting beta-2-adrenergic agonist (salmeterol) and holds a month's medication (60 inhalation doses) [20]. It is indicated for the long-term, twice-daily, maintenance therapy of asthma and chronic obstructive pulmonary disease. The device is made of a molded thermoplastic polymer and consists of the following key parts: mouthpiece; dose delivery lever; dose counter; thumb grip and; the outer case. It is operated via four simple steps: first, open the mouthpiece cover; second, slide the lever until you hear it click; third, inhale the medication and; fourth, close the mouthpiece cover $[20,21]$.

There is an electronic monitor to record the date and time of drug delivery from the Advair Diskus called the Diskus Adherence Logger (DAL) [22]. The DAL module consists of three subunits: the data collection unit; an interface unit and; a computer software unit. The DAL module works by identifying the movement of the dose delivery lever and subsequent storing for the instance at which the dose delivery lever movement is identified. Therefore, there are two key tasks to be accomplished: the initiation of a 'dose delivery lever moved' signal and the documentation of that signal [22]. In the DAL module, the 'dose delivery lever moved' indication is captured by a small, low-power Hall-effect magnetic switch, while the electronic file utilizes a remarkably engineered trackrecording microprocessor. The data gathering unit are charged by a small $3 \mathrm{~V}$ lithium button-cell battery, while the interface unit needs no battery since it is powered directly by the universal serial bus port. DAL manufacturing is quite easy since there are no automatic or moving elements to fabricate. It can be easily attached or detached from the inhaler device's outer case using double-sided tape. Additionally, from the clinician's perspective, the important data like user identification, time and date of therapy can be easily uploaded into the DAL module using the universal serial bus port [22]. Briefly, the simplicity of manufacturing and ease of the DAL helps to make clinical application and distribution of this technology practicable.

\section{ProAir Digihaler device}

The Digihaler is a novel inhaler technology developed by Teva Pharmaceutical Industries, Israel [23]. It is a multi-dose breath-actuated inhaler designed to appear like a typical pressurized metered-dose inhaler, but its internal geometry and working is very unique. ProAir Digihaler is an inhaler device that efficiently delivers albuterol $(90 \mu \mathrm{g})$ from the mouthpiece per actuation. ProAir Digihaler is indicated for the treatment or prevention of bronchospasm with reversible obstructive airway disease and prevention of exercise-induced bronchospasm in patients four years of age and older. It is supplied with 200 inhalation doses, involves no cleaning and is disposable once all the doses have been actuated [23,24]. The ProAir Digihaler works via three easy steps: open the mouthpiece cover; inhale the dose and; close the mouthpiece cover. The device is made of a molded thermoplastic polymer, in other words, acrylonitrile butadiene styrene and consists of the following key components: drug reservoir; spacer; deagglomeration cup; dose metering system; reservoir pressure system and; dose counting system [25].

Additionally, the ProAir Digihaler contains two major components: built-in electronic module with lithiummanganese dioxide battery and; a companion mobile application to automatically notice and store the data on inhaler events [11]. The electronic module mainly consists of a pressure sensor, a wireless transmitter (bluetooth system) and a processor [11]. The ProAir Digihaler pressure sensor is made up of barometric type MEMS with the capacity of sensing the extremely small pressure change $(\leq 1 \mathrm{~Pa})[11]$. The pressure sensor port is pneumatically attached to a mouthpiece and easily senses all inhaler activities ranging from the mouthpiece cover opening to the dosing mechanism of the inhaler. The real-time inhaler information recorded by MEMS can be easily shared with the patient and/or caregiver through near field communication technology, in other words, 'bluetooth' (bluetooth low energy module). As well, if no dosing information is sensed within a fixed period following, a scheduled dosing time, near field communication will send a reminder to the patient and/or caregiver [11]. Moreover, the inhaler monitoring module also comprises a light-emitting diode to indicate the functioning state of the monitoring module. The inhaler-usage data are transmitted to the linked mobile application by a wireless bluetooth module, so users can scrutinize their records in time and communicate it with their clinicians [11]. Therefore, the Digihaler device has a good potential to be explored as a routine clinical technique for understanding patient adherence and compliance to long-term inhalation therapy. 


\section{Electronic Breezhaler}

The Breezhaler device is a single-dose inhaler device that is prescribed to deliver capsules holding indacaterol maleate (Onbrez ${ }^{\circledR}$ Breezhaler), glycopyrronium bromide (Seebri ${ }^{\circledR}$ Breezhaler) and glycopyrronium bromide/indacaterol maleate (Ultibro ${ }^{\circledR}$ Breezhaler) for the treatment of various pulmonary diseases. The Breezhaler device is made of acrylonitrile butadiene styrene and consists of the following components: mouthpiece tube; capsule chamber; tangentially positioned air inlets; capsule-piercing means with push buttons and; a removable cap. To utilize the inhaler device, the user places a capsule into a chamber. After securing the mouthpiece, the two push-button is pressed, piercing the capsule at both edges, the user then inhales through the mouthpiece tube, which causes the capsule to spin within the device chamber and this generates a typical 'whirring' sound, as the capsule rotates. Besides, users can observe that they have inhaled all the formulation as the capsule is transparent. As a result, users obtain instant and straight feedback that the dose has been taken suitably, as they can observe that the capsule is emptied and can hear the capsule spin within the chamber. However, to improve the effective dialogue between clinicians and patients during long-term maintenance therapy, Novartis Pharma with the help of Propeller Health (USA) have designed and developed a digital inhaler monitoring device, in other words, Enerzair Breezhaler [26,27].

Recently, the European Medicines Agency approved the Enerzair Breezhaler, the first asthma triple combination therapy (indacaterol, glycopyrronium and mometasone furoate). The device sensor comprises a microchip, a microphone, a bluetooth system, a battery and an antenna. The sensor can be easily attached to the base of the inhaler to gather data on the use of the inhaler by the patient. The data can be easily transferred to an app on a Smartphone [26,27]. Further regulatory assessments for Enerzair Breezhaler are currently ongoing in several countries.

\section{SmartDisk}

The SmartDisk device is another electronic monitor developed to record the data of drug delivery from the Advair Diskus $[10,28]$. It has been designed and developed to incorporate a more informative user interface. Particularly, the SmartDisk device comprises an LED display and four keys that permit the navigation within the device menu that contains data regarding inhaler use, battery charge level and permitting the selection of reminder alarms $[10,28]$. The SmartDisk device can notice and record the movement of the dose delivery lever and the inhaler actuation events. Moreover, the universal serial bus port and bluetooth connectivity are also available to quickly store and share the inhaler usage data. The SmartDisk devices have been exercised for validating the effects of clinician prescribing patterns on the adherence of therapy in children with pulmonary complications. The SmartDisk was also used to understand the key limitations to adherence, comprising parent and child-associated parameters within a long-term investigation, showing the difficulty of adherence optimization in children [10,28].

Obesity is allied with asthma and is responsible for a greater healthcare socioeconomic burden. Therefore, active researchers and clinicians from the University of Colorado Denver, USA are studying the behavioral and biologic inter-relationships between obesity and asthma conditions, using a digital inhaler device. Particularly, researchers are conducting an observational prospective, cohort study of obese asthmatic patients $(n=400)$ with SmartDisk equipped inhaler devices to develop counseling and educational modules for integrated self-management therapy [29]. Further clinical studies for the SmartDisk are ongoing in several universities and research institutes.

\section{SmartTurbo}

Turbuhaler ${ }^{\circledR}$ (AstraZeneca, UK) is a multi-dose DPI that is generally utilized to deliver several actives, in other words, terbutaline sulphate (Bricanyl ${ }^{\circledR}$ Turbuhaler), budesonide (Pulmicort ${ }^{\circledR}$ Turbuhaler) and budesonide/formoterol combination (Symbicort ${ }^{\circledR}$ Turbuhaler) for the treatment of pulmonary ailments [30,31]. The Turbuhaler device can be filled with drug substances to offer at least 200 doses and every single dose is delivered by a simple turning process [30,31]. The Turbuhaler device is made up of molded plastics, a spring with the steel and the device consists of the following key components: a mouthpiece, air inlet, inhalation channel, dose indicator, drug storage unit, dosing chamber and turning grip [30,31]. The dosing activity is carried out by simply moving the turning gripe back and forth. The turning gripe movement facilities the loading and emptying of the dosing chamber. The Turbuhaler device dosing system worked on the volumetric principle [30,31].

The SmartTurbo device is the inhaler tracker system developed to monitor and record the data of drug delivery from the Turbuhaler [32]. The SmartTurbo device can be easily attached or detached from the standard Turbuhaler inhaler device turning grip [10,32]. The SmartTurbo device uses proprietary electro-mechanical sensors and a torque switch mechanism to record the presence or absence of the cap on the mouthpiece and to sense the completion turning gripe needed for the correct administration of powder, respectively. The SmartTurbo software 
is a software designed to register a medication delivery incident and data to be shared using the Smartinhaler Connection Centre program [32]. Recently, Pilcher $e t$ al. performed a 12-week bench testing to determine the accuracy of the Smart Turbo in recording and monitoring the actuation from the Turbuhaler device. The bench testing was performed with the Symbicort Turbuhaler [budesonide/formoterol 400/12 $\mu \mathrm{g}$ /actuation ( $\mathrm{n}=5$ ), 200/6 $\mu \mathrm{g}$ per actuation $(\mathrm{n}=12)$ and $100 / 6 \mu \mathrm{g} /$ actuation $(\mathrm{n}=3)]$. The actuation events were properly recorded by the SmartTurbo device with a satisfactory accuracy of $99.9 \%$. Therefore, Pilcher $e$ t al. are currently working to execute the real-world validation study [32]. Concisely, the SmartTurbo is easy to accept at the laboratory level to carry out observational and benchmark experiments.

\section{Conclusion}

The inhaler device is the most important factor in long-term therapy of pulmonary diseases. Several electronic monitoring devices are discussed systematically in the present commentary to understand therapy adherence and inhaler handling techniques. The majority of monitoring devices are compatible with both multi-dose (blister) and single-dose (capsule) based-inhaler devices. Monitoring devices not only permit primary therapy adherence monitoring but can also offer in-depth data regarding the inhaler handling technique and pulmonary fitness such as inhaler resistance, inhalation volume and peak inspiratory flow more precisely. This detailed data can be utilized in both clinical practice and clinical research to scrutinize the success of long-term therapy. The quick feedback, dose reminder and easy workstation connectivity shows a versatile tool that can adapt to successfully tailor interventions and treatment schemes. Briefly, monitoring devices offer a ready solution for long-term patient monitoring, adherence improvement and inhaler handling.

\section{Acknowledgments}

The author thanks Bharati Vidyapeeth University, Poona College of Pharmacy, Pune 38, India for support and institutional facilities.

\section{Financial \& competing interests disclosure}

The author has no relevant affiliations or financial involvement with any organization or entity with a financial interest in or financial conflict with the subject matter or materials discussed in the manuscript. This includes employment, consultancies, honoraria, stock ownership or options, expert testimony, grants or patents received or pending, or royalties.

No writing assistance was utilized in the production of this manuscript.

\section{References}

Papers of special note have been highlighted as: $\bullet$ of interest; $\bullet \bullet$ of considerable interest

1. Forum of International Respiratory Societies. The Global Impact of Respiratory Disease(2nd Edition). European Respiratory Society, Sheffield, UK (2017).

2. Mehta PP, Ghoshal D, Pawar AP et al. Recent advances in inhalable liposomes for treatment of pulmonary diseases: concept to clinical stance. J. Drug Deliv. Sci. Technol. 56, 101509 (2020).

3. Mehta PP, Pawar AP, Mahadik KR et al. Dry powder coating techniques and role of force controlling agents in aerosol. In: Polymer Coatings: Technology and Applications. Inamuddin (Ed.). Scrivener Publishing LLC, Beverly, MA, USA, 41-72 (2020).

-. A thorough review of dry powder coating and force controlling agents used in dry powder inhalers (DPIs).

4. Mehta PP. Dry powder inhalers: upcoming platform technologies for formulation development. Ther. Deliv. 10, 551-554 (2019).

5. Mehta PP. Dry powder inhalers: a brief overview of the drug detachment techniques. Ther. Deliv. 11, 139-143 (2020).

6. Restrepo RD, Alvarez MT, Wittnebel LD et al. Medication adherence issues in patients treated for COPD. Int. J. Chron. Obstruct. Pulmon. Dis. 3, 371-384 (2008).

7. Bourbeau J, Bartlett S. Patient adherence in COPD. Thorax 63, 831-838 (2008).

- Comprehensive account of patient adherence and compliance to pulmonary therapy.

8. Fink J. Inhalers in asthma management: is demonstration the key to compliance? Respir. Care 50, 598-600 (2005).

9. von Schantz S, Katajavuori N, Juppo A. The use of video instructions in patient education promoting correct technique for dry powder inhalers: an investigation on inhaler-naïve individuals. Pharmacy (Basel). 6, E106 (2018).

10. Kikidis D, Konstantinos V, Tzovaras D et al. The digital asthma patient: the history and future of inhaler based health monitoring devices. J. Aerosol Med. Pulm. Drug Deliv. 29, 219-232 (2016).

$\bullet \quad$ Detailed explanation of health monitoring devices. 
11. Morrison M, Weitzel D, Oliveras E et al. Compliance monitoring module for a breath-actuated inhaler. US20160339190A1 (2016). https://patents.google.com/patent/US20160339190A1/en?q=Compliance+monitoring+module+breath-act uated+inhaler.\&oq=Compliance+monitoring+module+for+a+breath-actuated+inhaler

12. Braido F, Paa F, Ponti L et al. A new tool for inhalers' use and adherence monitoring: the Amiko ${ }^{\circledR}$ validation trial. Int. J. Eng. Res. Sci. 2, 159-166 (2016).

13. Rogueda P, Grinovero M, Ponti L et al. Telehealth ready: performance of the AmikoRespiro Sense connected technology with Merxin DPIs. Presented at: Drug Delivery to the Lungs. (2018). https://aerosol-soc.com/wp-content/uploads/2018/10/22.Rogueda.poster.pdf

14. Moran C, Doyle F, Sulaiman I et al. The INCA ${ }^{\mathrm{TM}}$ (Inhaler Compliance Assessment ${ }^{\mathrm{TM}}$ ): a comparison with established measures of adherence. Psychol. Health 32, 1266-1287 (2017).

-. A detailed account of Inhaler Compliance Assessment ${ }^{\top M}$ with special emphasis on its mechanisms and working.

15. Greene G, Costello RW, Cushen B et al. A novel statistical method for assessing effective adherence to medication and calculating optimal drug dosages. PLoS ONE 13, e0195663 (2018).

16. Taylor TE, Zigel Y, Egan C et al. Objective assessment of patient inhaler user technique using an audio-based classification approach. Sci. Rep. 8, 1-4 (2018).

17. Sulaiman I, Greene G, MacHale E et al. A randomised clinical trial of feedback on inhaler adherence and technique in patients with severe uncontrolled asthma. Eur. Respir. J. 51, 1701126 (2018).

18. van Boven JF, Cushen B, Sulaiman I, et al. Personalising adherence-enhancing interventions using a smart inhaler in patients with COPD: an exploratory cost-effectiveness analysis. NPJ Prim. Care Respir. Med. 28, 1-3 (2018).

19. Seheult JN, O'Connell P, Tee KC et al. The acoustic features of inhalation can be used to quantify aerosol delivery from a Diskus dry powder inhaler. Pharm. Res. 31, 2735-2747 (2014).

20. Atkins PJ. Dry powder inhalers: an overview. Respiratory Care 50, 1304-1312 (2005).

21. Chrystyn H. The Diskus ${ }^{\mathrm{TM}}$ : a review of its position among dry powder inhaler devices. Int. J. Clin. Pract. 61, 1022-1036 (2007).

22. Bogen D, Apter AJ. Adherence logger for a dry powder inhaler: a new device for medical adherence research. J. Allergy Clin. Immunol. 114, 863-868 (2004).

23. Proair $\left(\right.$ Digihaler $^{\top M}$, prescribing information. Proair ${ }^{\circledR}$ Digihaler $^{T M}$ (albuterol sulfate) inhalation powder, for oral inhalation. www.accessdata.fda.gov/drugsatfda_docs/label/2019/205636Orig1s012lbl.pdf

24. Teva Respiratory, LLC, Frazer, PA, USA. Proair ${ }^{\circledR}$ Digihaler $^{T M}$ (albuterol sulfate) inhalation powder, for oral inhalation. www.proairdigihaler.com/globalassets/proair_digihaler/Proair_Digihaler_PIL.pdf

25. Mehta P. Multi-dose dry powder inhaler: advance technology for drug delivery to airways. Indian Drugs 56, 59-62 (2019).

-. A detailed account of multi-dose DPI (RespiClick ${ }^{\circledR} /$ Spiromax $\left.^{\circledR}\right)$ with special emphasis on its dose metering system and deagglomeration mechanism.

26. Enerzair ${ }^{\circledR}$ Breezhaler ${ }^{\circledR}$. Summary of product characteristics. www.ema.europa.eu/en/documents/product-information/enerzair-breezhaler-epar-product-information_en.pdf

27. Enerzair ${ }^{\circledR}$ Breezhaler ${ }^{\circledR}$. www.ema.europa.eu/en/medicines/human/EPAR/enerzair-breezhaler\#product-information-section

28. Chan AH, Harrison J, Black PN, Mitchell EA, Foster JM. Using electronic monitoring devices to measure inhaler adherence: a practical guide for clinicians. J. Allergy Clin. Immunol. Pract. 3, 335-349 (2015).

29. Clinical Trials.gov Identifier: NCT03460834.. Asthma and obesity: observational. https://clinicaltrials.gov/ct2/show/NCT03460834?term=SmartDisk\&draw=1\&rank=1

30. Wetterlin K. Turbuhaler: a new powder inhaler for administration of drugs to the airways. Pharma. Res. 5, 506-508 (1988).

-. A detailed account of multi-dose DPI (Turbuhaler ${ }^{\circledR}$ ) with special emphasis on its dose delivery and metering system.

31. Milenkovic J, Alexopoulos AH, Kiparissides C. Flow and particle deposition in the Turbuhaler: a CFD simulation. Int. J. Pharma. 448, 205-213 (2013).

- A thorough explanation of Turbuhaler with help of fluid dynamics.

32. Pilcher J, Shirtcliffe P, Patel M et al. Three-month validation of a Turbuhaler electronic monitoring device: implications for asthma clinical trial use. BMJ Open Resp. Res. 2, e000097 (2015). 